\title{
Effect of $\gamma$-Irradiation on the Molecular Properties of Myoglobin
}

\author{
Yongwoo Lee and Kyung Bin Song* \\ Department of Food Science and Technology, College of Agriculture and Life Sciences, \\ Chungnam National University, Taejon 305-764, Korea
}

Received 8 August 2002, Accepted 14 September 2002

To elucidate the effect of gamma-irradiation on the molecular properties of myoglobin, the secondary and tertiary structures, as well as the molecular weight size of the protein, were examined after irradiation at various irradiation doses. Gamma-irradiation of myoglobin solutions caused the disruption of the ordered structure of the protein molecules, as well as degradation, crosslinking, and aggregation of the polypeptide chains. A SDSPAGE study indicated that irradiation caused initial fragmentation of the proteins and subsequent aggregation, due to cross-linking of the protein molecules. The effect of irradiation on the protein was more significant at lower protein concentrations. Ascorbic acid protected against the degradation and aggregation of proteins by scavenging oxygen radicals that are produced by irradiation. A circular dichroism study showed that an increase of the irradiation decreased the $\alpha$-helical content of myoglobin with a concurrent increase of the aperiodic structure content. Fluorescence spectroscopy indicated that irradiation increased the emission intensity that was excited at $280 \mathrm{~nm}$.

Keywords: Irradiation, Molecular properties, Myoglobin

\section{Introduction}

Chemical changes of the proteins that are caused by $\gamma$ irradiation are fragmentation, cross-linking, aggregation, and oxidation by oxygen radicals that are generated in the radiolysis of water (Schuessler and Schilling, 1984; Filali-Mouhim et al., 1997; Cho and Song, 2001). The effect of $\gamma$-irradiation on the protein conformation appeared to depend on several factors, such as protein concentration, the presence of oxygen and an oxygen scavenger, and the quaternary structure of the proteins.

*To whom correspondence should be addressed.

Tel: 82-42-821-6723; Fax: 82-42-825-2664

E-mail: kbsong@cnu.ac.kr
The hydroxy and superoxide anion radicals that are generated by radiation could modify the primary structure of the proteins, which would result in distortions of the secondary and tertiary structures (Davies and Delsignore, 1987).

Irradiation caused irreversible changes at the molecular level by breakage of the covalent bonds of the polypeptide chains. The exposure of proteins to oxygen radicals resulted in both non-random and random fragmentations (Kempner, 1993). The protein fragmentation in aqueous solutions is affected by the local conformation of an amino acid in the protein, its accessibility to the water radiolysis products, and the primary amino acid sequence (Filali-Mouhim et al., 1997). There have been reports on the aggregation and cross-linking of proteins by irradiation (Garrison, 1987; Puchala and Schessler, 1993; Filali-Mouhim et al., 1997). Covalent crosslinkages are formed between free amino acids and proteins, and between peptides and proteins in solution after irradiation (Garrison, 1987).

The radiation-induced alteration of the protein structure was observed by measuring the changes in the molecular properties of the proteins in our previous studies (Cho and Song, 2000; Moon and Song, 2001). Myoglobin is one of the major proteins of meat products, which are subjected to ionizing radiation for an extension of the shelf life of food products. Therefore, to further elucidate the effect of $\gamma$ irradiation on the molecular properties of myoglobin in irradiated meat products, the irradiation effect on the secondary and tertiary structures, as well as the molecular weight size of myoglobin and the effect of the protein concentration and oxygen scavenger, were studied.

\section{Materials and Methods}

Materials Horse skeletal muscle myoglobin was purchased from the Sigma Chemical Co. (St. Louis, USA) and used without further purification. Standard marker proteins for SDS-PAGE were obtained from Bio-Rad Inc. (Richmond, USA).

Sample irradiation Ten $\mathrm{ml}$ solutions of myoglobin in a $10 \mathrm{mM}$ phosphate buffer $(\mathrm{pH}$ 7.0) were added in borosilicate glass vials 
$(16 \times 125 \mathrm{~mm})$ and irradiated at $0,0.5,1,5$, and $10 \mathrm{kGy}$ using a ${ }^{60} \mathrm{Co}$ gamma ray irradiator Type IR-79 (Nordion International Inc., Ontario, Canada). The ${ }^{60} \mathrm{Co}$ exposure varied from 6 to $189 \mathrm{~cm}$ in order to achieve total doses of 0.5-10 kGy. The dose rates were 0.5 , 1,5 , and $10 \mathrm{kGy} / \mathrm{h}$.

SDS-PAGE SDS-PAGE was performed according to the method of Laemmli (1970). Equal amounts of the protein samples were loaded on each lane for comparison, resolved on a $15 \%$ separation gel, and stained with Coomassie Brilliant Blue. The following molecular weight markers were used: rabbit skeletal muscle myosin $(200 \mathrm{kDa})$, E. coli $\beta$-galactosidase $(116 \mathrm{kDa})$, rabbit muscle phosphorylase $\beta$ (97 kDa), bovine serum albumin (66.2 kDa), egg white ovalbumin $(45 \mathrm{kDa})$, bovine carbonic anhydrase (31 kDa), soybean trypsin inhibitor $(21.5 \mathrm{kDa})$, hen egg white lysozyme $(14.4 \mathrm{kDa})$, and bovine pancreatic trypsin inhibitor $(6.5 \mathrm{kDa})$.

UV absorbance spectrum UV-visible spectra of irradiated myoglobin were obtained using a UV-visible spectrophotometer (S2130, Scinco Co., Seoul, Korea).

Circular dichroism (CD) measurements CD spectroscopy was performed at $25^{\circ} \mathrm{C}$ with a JASCO J-720 spectropolarimeter, according to the method reported previously (Lee and Song, 1997; Cho and Song; 1997; Moon and Song; 2001). A 1-mm-pathlength cell was used. The reported CD spectra were the average of five scans, and were smoothed by the polynomial curve-fitting program and analyzed by the method of Yang et al. (1986). CD data were expressed as molar ellipticity in $\mathrm{deg} \cdot \mathrm{cm}^{2} \cdot \mathrm{dmol}^{-1}$.

Fluorescence spectroscopy Fluorescence emission intensity of the irradiated myoglobin solution was measured using a spectrofluorometer (JASCO FP-750, Tokyo, Japan). The irradiated protein solutions were excited at $280 \mathrm{~nm}$. The emission spectra were recorded from 300 to $450 \mathrm{~nm}$.

\section{Results and Discussion}

Two types of radiation damage to proteins were observedfragmentation and aggregation (Filali-Mouhim et al., 1997; Cho and Song, 2001; Moon and Song, 2001). SDS-PAGE profiles of the myoglobin showed that $\gamma$-irradiation at lowdose ranges caused a slight breakdown of the polypeptide chain. It also showed some of the small molecular weight molecules as smeared degraded bands with a concurrent decrease of a major band intensity under loading of the same amount of protein, especially at a $0.1 \%$ protein concentration (Fig. 1A). Similar results were observed in other studies (Le Maire et al., 1990; Cho and Song, 2000; Moon and Song, 2001). Usually, the breakage of the covalent bonds in irradiated proteins is shown as new bands below the major band. Above $5 \mathrm{kGy}$ of the dose (on a SDS-PAGE gel, Fig. $1 \mathrm{~A})$, there was only a degraded pattern of protein molecules with some of the aggregated molecules that could not penetrate the separating gel. An $\gamma$-irradiation increase caused the degradation of the protein molecules. Eventually at high dose ranges of 5 and $10 \mathrm{kGy}$, there was a significant increase in the size of the protein molecules, which were cross-linked products of the degraded protein molecules. A similar result was observed in the case of hemoglobin, another hemoprotein (Puchala and Schuessler, 1993). When hemoglobin was irradiated in a phosphate buffer at $\mathrm{pH} 7$ under air, aggregation as well as fragmentation was also observed.

The protein concentration affected the degree of conformational change of the irradiated proteins. In general, irradiation is more significant at a low protein concentration (Krumhar and Berry, 1990; Moon and Song, 2001). This was consistent with our observation, where at a low protein concentration, the effect of irradiation was more significant (Fig. 1). In the range of $0.1-0.5 \%$ of the protein, the SDS-PAGE
(A)

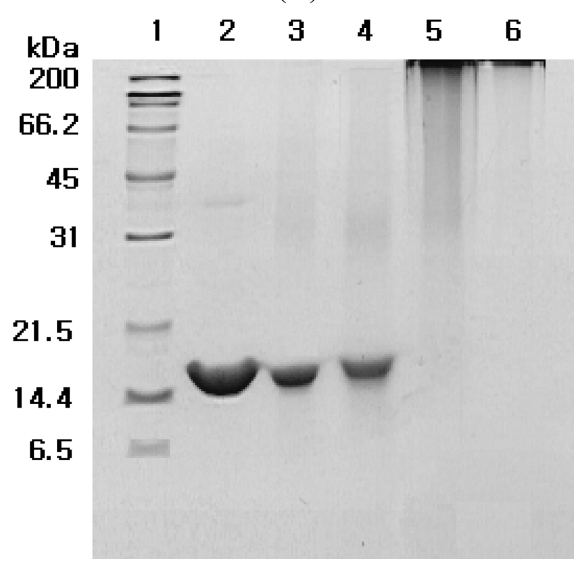

(B)

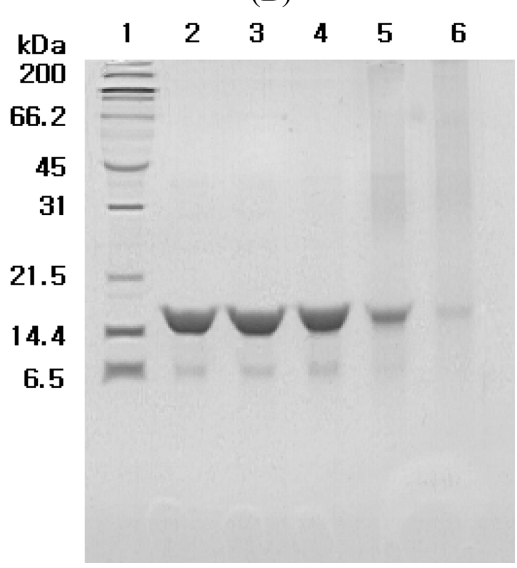

(C)

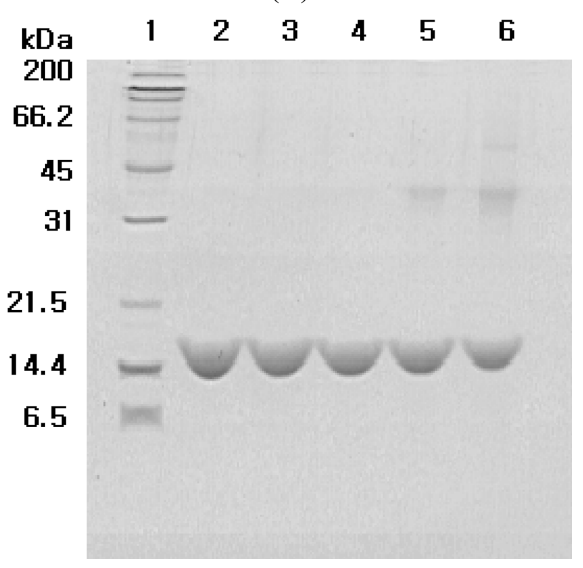

Fig. 1. SDS-PAGE profile of irradiated myoglobin. Equal amounts of the protein samples $(10 \mu \mathrm{g})$ were loaded on each lane for comparison, resolved on a $15 \%$ separation gel, and stained with Coomassie Brilliant Blue. (A) $0.1 \%$ myoglobin (B) $0.5 \%$ myoglobin (C) 5\% myoglobin, Molecular weight marker (1); O kGy (2); 0.5 kGy (3); 1 kGy (4); 5 kGy (5); 10 kGy (6). 


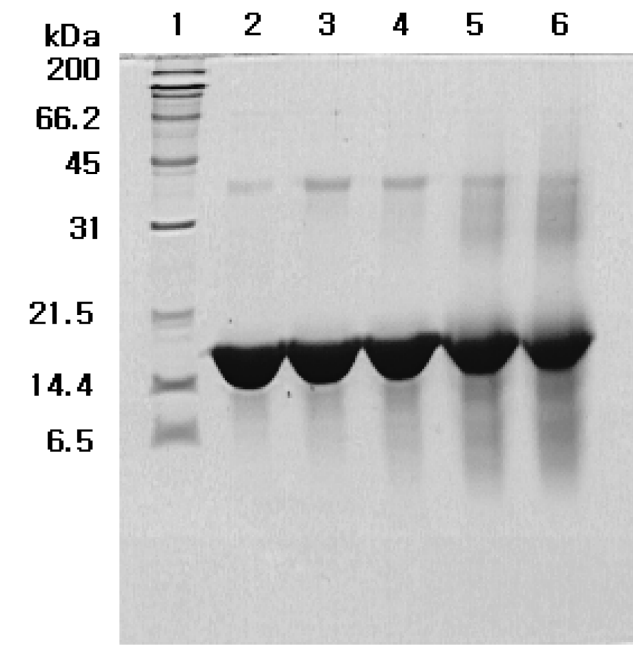

Fig. 2. SDS-PAGE profile of irradiated myoglobin $(0.1 \%)$ in the presence of ascorbic acid. Equal amounts of the protein samples $(15 \mu \mathrm{g})$ were loaded on each lane. Molecular weight marker (1); O kGy (2); 0.5 kGy (3); 1 kGy (4); 5 kGy (5); 10 kGy (6).

profile of irradiated myoglobin at $10 \mathrm{kGy}$ mainly showed an aggregated pattern of protein bands with smeared degraded bands (Fig. 1A-B). However, at a 5\% concentration, irradiation did not significantly affect the molecular weight profile of myoglobin when compared to the unirradiated one (Fig. 1C).

Proteins can be converted to higher molecular weight aggregates, due to the generation of inter-protein cross-linking reactions, hydrophobic and electrostatic interactions, as well as the formation of disulfide bonds (Davies and Delsignore, 1987; Le Maire et al., 1990). Any amino acid radical that is formed within a peptide chain could cross-link with an amino acid radical in another protein. The formation of highmolecular weight aggregates was negligible at a low-dose range, but increased significantly at higher doses (Fig. 1).

Ascorbic acid protects against the aggregation of irradiated proteins by scavenging oxygen radicals that are generated by the radiolysis of water (Yoshimura et al., 1993; Moon and Song, 2001). Figure 2 shows that ascorbic acid protected against the aggregation of irradiated myoglobin and compares well with Figure 1A. Especially at 5 and $10 \mathrm{kGy}$, the major band of myoglobin was intact, indicating that the native protein was conserved by the scavenging-oxygen radicals. This was also confirmed at various irradiated protein concentrations at $10 \mathrm{kGy}$, which was the highest irradiation dose and the most significant change of molecular weight profile that could be observed (Fig. 3). For all of the protein concentration ranges that were studied, ascorbic acid as an oxygen scavenger unambiguously protected the aggregation of protein molecules that is caused by oxygen radicals that are produced by irradiation.

Myoglobin is a well-known hemoprotein. The heme is located in the hydrophobic pocket. Part of the heme surface is exposed to the solvent (Stellwagen, 1978; Li et al., 2000). UV-

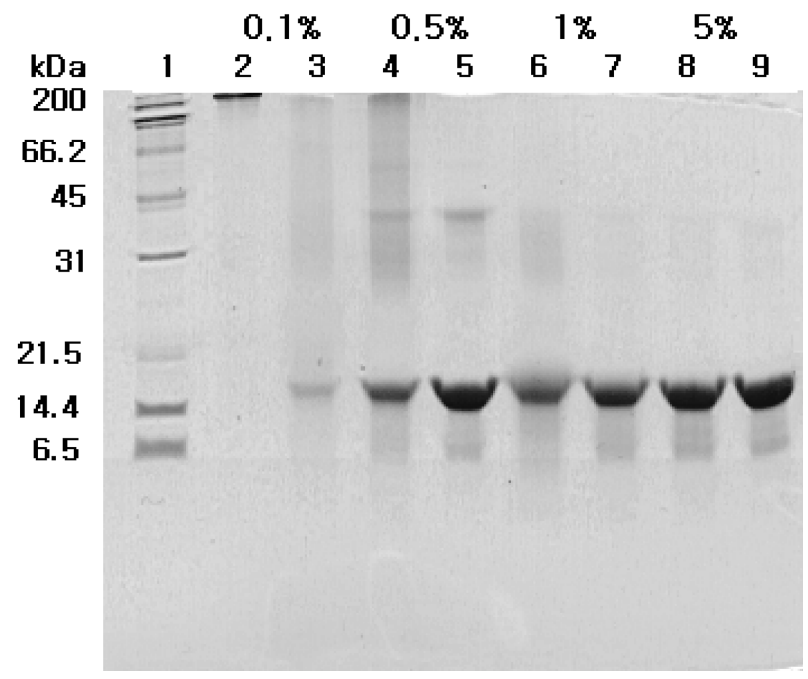

Fig. 3. SDS-PAGE profile of irradiated myoglobin at $10 \mathrm{kGy}$ in the presence of ascorbic acid. Molecular weight marker (1); myoglobin $0.1 \%(2,3) ; 0.5 \%(4,5) ; 1 \%(6,7) ; 5 \%(8,9)$; Lanes 2, 4, 6, and 8 in the absence of ascorbic acid; Lanes 3, 5, 7 , and 9 in the presence of $0.2 \%$ ascorbic acid.

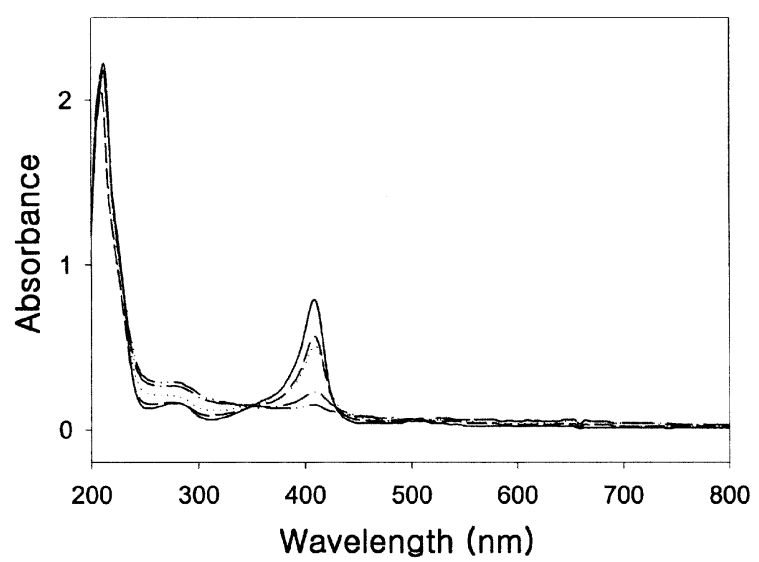

Fig. 4. UV absorbance spectra of irradiated myoglobin $(0.1 \%)$. $10 \mathrm{kGy}$. 0 kGy; - - -, 0.5 kGy; ------, 1.0 kGy ; - - -, 5 kGy; - .. -,

visible spectrum of the myoglobin showed a typical spectrum of the protein that contained a heme group, which has an absorbance maximum around $409 \mathrm{~nm}$ (Fig. 4). However, irradiation disrupted the heme group, resulting in a decrease of the absorbance at $409 \mathrm{~nm}$. This discrepancy of absorbance can be easily used to determine the irradiation dose of irradiated myoglobin by simply measuring the absorbance at $409 \mathrm{~nm}$. Also, it should be noticed that absorbance slightly increased at $280 \mathrm{~nm}$, which reflects the exposure of the tryptophanyl residue to the protein surface by irradiation.

Far-UV CD spectra showed the conformational change on the secondary structure of the proteins. In the case of a change in the local environment of the ordered structure of a polypeptide chain, it was particularly easily differentiated 


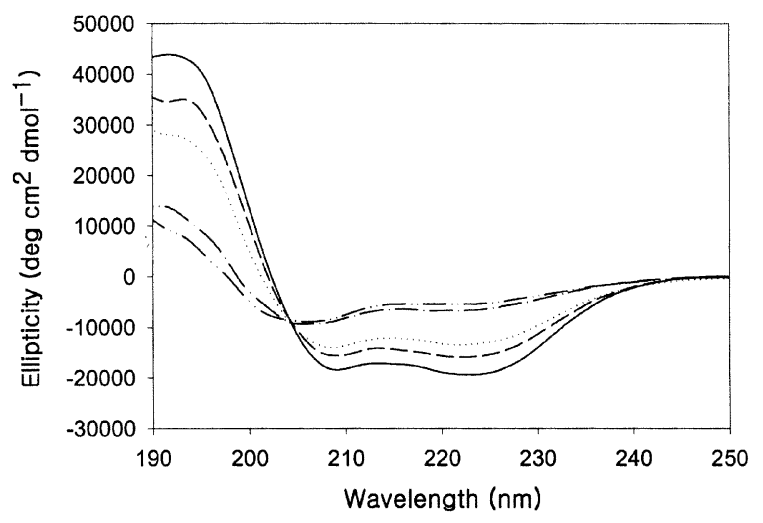

Fig. 5. CD Spectra of myoglobin $(0.1 \%)$ irradiated. CD spectroscopy was performed at $25^{\circ} \mathrm{C}$. A 1-mm-pathlength cell was used. The reported CD spectra were the average of five scans, and were smoothed by the polynomial curve-fitting program. __, 0 kGy; - - -, 0.5 kGy; -----, $1.0 \mathrm{kGy} \mathrm{;} \mathrm{-} \mathrm{-} \mathrm{-,} 5$ kGy; - .. -, 10 kGy.

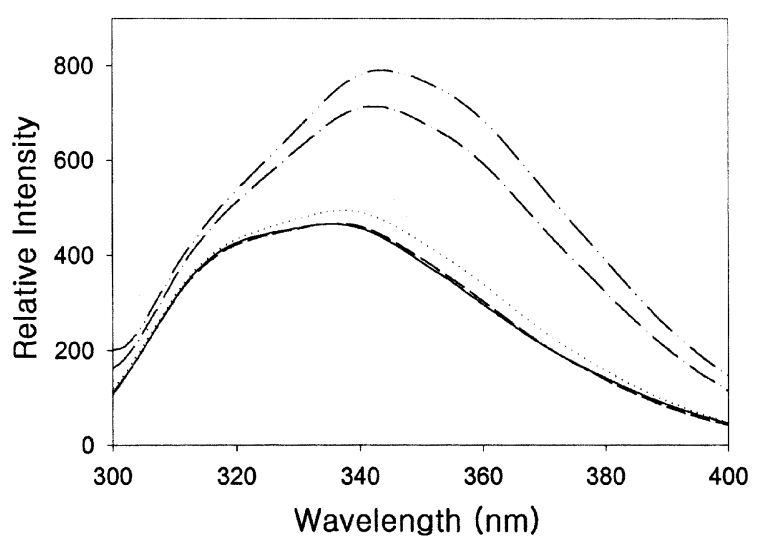

Fig. 6. Fluorescence emission spectra of irradiated myoglobin. Irradiated protein solutions $(1 \%)$ were excited at $280 \mathrm{~nm}$. The emission spectra were recorded from 300 to $450 \mathrm{~nm}$. $\longrightarrow 0$ kGy; - - -, 0.5 kGy; ------, 1.0 kGy ; - - -, 5 kGy; -.. -, 10 kGy.

from the native one. Far-UV CD spectra of the irradiated myoglobin solution at various doses were obtained (Fig. 5). The spectrum of native myoglobin had a typical $\alpha$-helical structure, which had negative minimum ellipticity values at 207 and $221 \mathrm{~nm}$, and a positive maximum at $193 \mathrm{~nm}$. Myoglobin consists of eight helices that surround the heme group (Moczygemba et al., 2000). However, g-irradiation clearly affected the $\mathrm{CD}$ spectrum and disrupted the globin fold. With an increase of irradiation, ellipticity values at 207 and $221 \mathrm{~nm}$ decreased. It primarily decreased the ordered structure, which resulted in a decrease of the a-helical structure with a concomitant increase of the random coil structure. Oxidative polypeptide chain fragmentation by oxygen radicals subsequently destabilized the $\alpha$-helical structure of the proteins. This was also confirmed by an estimation of the secondary structure content by the method of Yang et al. (1986). Table 1 clearly shows that $\gamma$-irradiation
Table 1. Estimation of secondary structure content of irradiated myoglobin

\begin{tabular}{ccccc}
\hline $\begin{array}{c}\text { Radiation } \\
\text { Dose } \\
\text { (kGy) }\end{array}$ & $\alpha$-Helix & $\beta$-Sheet & $\beta$-Turn & $\begin{array}{c}\text { Random } \\
\text { coil }\end{array}$ \\
\cline { 2 - 5 } & \multicolumn{5}{c}{$(\%)$} \\
0 & 63 & 0 & 14 & 23 \\
0.5 & 56 & 0 & 18 & 26 \\
1 & 41 & 0 & 23 & 36 \\
5 & 15 & 21 & 22 & 42 \\
10 & 12 & 19 & 25 & 44 \\
\hline
\end{tabular}

decreased the $\alpha$-helical structural content of myoglobin with a simultaneous increase of the random coil structure. Native myoglobin had a $67 \% \alpha$-helical content. This value was a little lower than the $79 \%$ that was reported (Chen et al., 1974; Yang et al., 1986; Takeda et al., 1988), due to use of a different method for the secondary structure estimation. Upon $\gamma$-irradiation, it decreased the $\alpha$-helical content to $12 \%$ with a concurrent increase of the random coil structure to $44 \%$. CD spectra changes of the protein by irradiation were mainly due to the cleavage of the covalent bonds of the proteins, and the formation of aggregated products. CD results clearly support that $\gamma$-irradiation easily breaks covalent bonds and disrupts the ordered structure of proteins, resulting in unnatural products of the proteins. This is also proved by the fact that some of irradiated enzymes lose their immunogenicity, as well as activity (Kume and Matsuda, 1995). This indicates that $\gamma$ irradiation at a very weak dose level can alter the native function of a protein.

To further examine the change on the molecular properties of myoglobin solutions by irradiation, the fluorescence emission intensity was measured. When excited at $280 \mathrm{~nm}$, which excites trytophan and tyrosine residues of protein, the tertiary structure of the protein is reflected. Figure 6 shows that $\gamma$-irradiation caused an increase in the emission intensity, due to the change of local environment around the trytophan and tyrosine residues. This change could be attributed to the difference in the tertiary structure of myoglobin.

In conclusion, this study clearly indicates that the molecular properties of myoglobin in meat products by $\gamma$-irradiation could be altered. The irradiated myoglobin could be differentiated from the native one by disruption of its heme group. Gamma-irradiation of the myoglobin solutions caused the disruption of the ordered structure of the protein molecules, as well as degradation, cross-linking, and aggregation of the polypeptide chains. Also, the effect of irradiation on the protein was more significant at a low protein concentration, and ascorbic acid protected against the degradation and aggregation of proteins by the scavenging oxygen radicals that were produced by irradiation. In particular, the treatment of ascorbic acid in the irradiation processing of meat products could be efficient in the prevention of possible damage to proteins. 


\section{References}

Chen, Y., Yang J. and Chau, K. (1974) Determination of the helix and beta form of proteins in aqueous solution by circular dichroism. Biochemistry 13, 3350-3359.

Cho, Y. and Song, K. B. (1997) Effect of chaotropic salt on the secondary structure of pig skin gelatin. Biosci. Biotech. Biochem. 61, 1194-1195.

Cho, Y. and Song, K. B. (2000) Effect of g-irradiation on the molecular properties of BSA and b-lactoglobulin. J. Biochem. Mol. Biol. 33, 133-137.

Davies, K. J. A. and Delsignore, M. E. (1987) Protein damage and degradation by oxygen radicals III. Modification of secondary structure and tertiary structure. J. Biol. Chem. 262, 9908-9913.

Filali-Mouhim, A., Audette, M., St-Louis, M, Thauvette, L., Denoroy, L., Penin, F., Chen, X., Rouleau, N, Le Caer, J. P., Rossier, J., Potier, M. and Le Maire, M. (1997) Lysozyme fragmentation induced by g-radiolysis. Int. J. Radiat. Biol. 72, 63-70.

Garrison, W. M. (1987) Reaction mechanisms in the radiolysis of peptides, polypeptides, and proteins. Chem. Rev. 87, 381-398.

Kempner, E. S. (1993) Damage to proteins due to the direct action of ionizing radiation. Quart. Rev. Biophys. 26, 27-48.

Krumhar, K. C. and Berry, J. W. (1990) Effect of antioxidant and conditions on solubility of irradiated food proteins in aqueous solutions. J. Food Sci. 55, 1127-1132.

Kume, T. and Matsuda, T. (1995) Changes in structural and antigenic properties of proteins by radiation. Radiat. Phys. Chem. 46, 225-231.

Laemlli, U. K. (1970) Cleavage of structural proteins during the assembly of the head of bacteriophage T4. Nature 227, 680685.

Lee, M. J. and Song, K. B. (1997) Purification of streptodornase from Streptococcus equisimilis and its DNA-induced conformational change. Biochem. Biophys. Res. Commun. 230, 13-15.

Le Maire, M., Thauvette, L., De Foresta, B., Viel, A., Beauregard, G. and Potier, M. Effects of ionizing radiations on proteins. Biochem. J. 267, 431-439.

Li, C., Nishiyama, K. and Taniguchi, I. (2000) Electrochemical and spectroelectrochemical studies on cobalt myoglobin. Electrochim. Acta 45, 2883-2888.

Moczygemba, C., Guidry, J. and Wittung-Stafshede, P. (2000) Heme orientation affects holo-myoglobin folding and unfolding kinetics. FEBS Lett. 470, 203-206.

Moon, S. and Song, K. B. (2001) Effect of gamma-irradiation on the molecular properties of ovalbumin and ovomucoid and protection by ascorbic acid. Food Chem. 74, 479-483.

Puchala, M. and Schessler, H. (1993) Oxygen effect in the radiolysis of proteins. Int. J. Radiat. Biol. 64, 149-156.

Schuessler, H. and Schilling, K. (1984) Oxygen effect in the radiolysis of proteins. Int. J. Radiat. Biol. 45, 267-281.

Stellwagen, E. (1978) Haem exposure as the determinate of oxidation-reduction potential of haem proteins. Nature 275, 7374.

Takeda K., Wada, A., Yamamoto K., Hachiya, K. and Batra, P. P. (1988) Secondary structure change of myoglobin induced by sodium dodecyl sulfate and its kinetic aspects. J. Colloid Interface Sci. 125, 307-313.

Wolff, S. P., Garner, A. and Dean, R. T. (1986) Free radicals, lipids and protein degradation. Trends Biochem. Sci. 11, 27-31.

Yang, J. T., Wu, C. and Martinez, H. M. (1986) Calculation of protein conformation from circular dichroism. Methods Enzymol. 130, 208-269.

Yoshimura, T., Matsuno, K., Miyazaki, T., Suzuki, K. and Watanabe, M. (1993) Electron spin resonance studies of free radicals in gamma-irradiated golden hamster embryo cells: radical formation at 77 and $295 \mathrm{~K}$, and radioprotective effects of vitamin C at 295K. Radiat. Res. 136, 361-365. 